\title{
ALN Teaching as Routine Faculty Workload
}

\author{
Gregory Hislop, Michael Atwood \\ Drexel University
}

\begin{abstract}
If the current growth in on-line education continues, teaching on-line will become part of routine faculty workload at many traditional, research-oriented universities. This is already occurring within some faculties, and this paper focuses on one of those cases. The paper describes faculty issues related to a completely on-line graduate degree in Information Systems at Drexel University. Following a brief overview, the paper presents results of a survey of the faculty affected by this degree. The survey addresses faculty support for the degree, and for the prospect of on-line teaching as a significant, permanent part of the work of the college.
\end{abstract}

\section{INTRODUCTION}

The College of Information Science and Technology (IST) at Drexel University began a long-term initiative in early 1994 to develop ALN capabilities [1]. The project has evolved through a series of phases with the general approach of building on earlier projects in computer-mediated communication. The goals of the most recent work at Drexel have centered on development of a fully asynchronous graduate degree, an M.S. in Information Systems (M.S.I.S.). Students accepted into the on-line program take all of their classes completely on-line and never need to come to campus.

A related case study [2] provides details on the background, development, and operation of the ALN degree program.

\section{RATIONALE}

This section discusses faculty considerations that led to the establishment of the on-line initiative.

\section{A. Initiative}

Faculty in IST started the ALN effort as a combined research and education project building on earlier efforts in online education [3]. Full-time faculty members have been involved with all phases of the project from course conversion to teaching, development, administration, and evaluation. The faculty of the College provided formal approval for delivering the degree via ALN. The project has also had administrative support all along, but the faculty role has been central to the form that this program has taken.

\section{B. Faculty Motivation}

A variety of factors affect faculty motivation for the ALN program.

- Early Adopters - The faculty who started the ALN project formed a natural group of early adopters. These faculty members performed the initial course conversion and teaching.

- Technical Skills - All of the faculty members teaching in the M.S.I.S. program have substantial technical ability and generally enjoy working with new technologies.

- Teaching Load and Compensation - Courses taught on-line count as a part of regular faculty teaching load, with on-line and traditional courses counting the same. To provide some additional 
incentive, faculty members teaching on-line also receive extra compensation. This compensation is intended to encourage people to try something new, and in recognition of the fact that most instructors feel that it takes more time to teach a class on-line. The amount of the compensation matches extra compensation paid to faculty for teaching classes at off-campus sites.

- Faculty Expansion - The faculty of the college has expanded substantially during the time we have been offering the on-line degree. New faculty members are hired with the understanding that they are likely to teach in the on-line program. On the other hand, we have not hired faculty specifically for on-line classes. All the faculty members who teach on-line also teach traditional classes. The only exceptions to this are two adjunct faculty members who taught in the traditional program but then moved out of the area. They have continued to teach via the on-line program.

- Performance Appraisal - The on-line initiative has strong support from the College administration, including the dean. This means that participation by faculty members in the on-line program is recognized as a desirable activity in the university performance appraisal process for faculty. At the same time, there has been a conscious effort to keep faculty reluctance to participate on-line from developing into a negative issue in performance appraisal. This is particular true for faculty members who were at the College before the on-line program began.

\section{BACKGROUND}

This section describes the faculty involved in the ALN program and discusses support provided for the ALN teaching work.

\section{A. Faculty}

Faculty who have participated in the on-line program reflect the full spectrum of faculty members in the College in many ways. At this point, a total of 18 faculty members have taught at least one course in the on-line program. This group includes all but a few of the full-time people who teach in the traditional M.S.I.S. Figure 1 shows a few relevant characteristics of the on-line faculty. The full-time people all hold doctorates, and generally have more teaching experience, with all but one of the full-time people having more than two years experience.

Another characteristic of the faculty that is typical for this College, but less usual in some others, is that all but one of the full-time people has significant experience working in industry (ranging approximately from 5 to 20 years). The part-time people all work full-time in industry in the area in which they teach. It is interesting to speculate whether this characteristic has any impact on our faculty's attitude toward faculty work and introduction of a change like on-line education. Perhaps the experience with varied and shifting responsibilities typical of jobs in industry or shorter tenure in academic positions makes this faculty more amenable to change.

\begin{tabular}{|l|l|c|}
\hline Rank & Full Professor & 4 \\
& Associate & 3 \\
& Assistant & 2 \\
& Instructor & 1 \\
& Research (Full-time) & 2 \\
& Adjunct (Part-time) & 6 \\
\hline Teaching Experience & 1-2 years & 5 \\
& 3-6 years & 6 \\
& 6 or more years & 7 \\
\hline Highest Degree & Ph.D. & 14 \\
& Master'ss & 4 \\
\hline
\end{tabular}

Figure 1. Characteristics of Faculty Members Who Have Taught On-line

A few of the faculty members teaching on-line have some experience teaching in other technology-enhanced distance education programs. None of the faculty has previously taught a course completely on-line. On the other hand, many of these people have regularly used technology in their traditional courses. This reflects the general 
technical environment of the University as well as the technical expertise of both the faculty and students in the College.

\section{B. Faculty Support}

There is no uniform approach to supporting individual faculty members who teach on-line. Rather, support is handled as part of the general support structure for the on-line program. Additional support is provided for individual instructors on a case-by-case basis.

Support for a faculty member's initial on-line teaching experience is provided in a semi-formal way. We have created some materials that an instructor can read to acquaint themselves with the background and approach to the on-line M.S.I.S. In addition, several of the early adopter group had served as mentors to faculty preparing to teach their first course on-line. However, our overall effort here has been uneven. As the on-line M.S.I.S. evolves from a start-up research project to a significant, ongoing part of routine operations, we see a need to improve our support for faculty teaching on-line for the first time. Our goals include expansion and refinement of the written materials, and a formal training and mentoring program.

\section{METHOD}

This section provides a brief overview of the approach to teaching and evaluating students, and the process used to convert courses for delivery on-line.

\section{A. Teaching Approach}

ALN capabilities can be applied in a variety of ways to structure individual courses. For our program we have chosen to emphasize the following aspects of ALN's potential:

- Instructor-led Study - An ALN instructor can present materials, explain things that students find difficult, provide motivation, evaluate, and re-direct where needed. Interactions can be informal and ad-hoc as well as formal and pre-defined.

- Group Work - Any degree program requires substantial individual work. ALN can support this and also support group work such as discussion and team projects. For graduate professional education, group work is particularly important since students can learn a great deal from each other. This is especially true in a program such as ours where the students are working professionals. ALN group work has a secondary benefit in that students develop skills in network-based communication. This should leave them well positioned to succeed in today's increasingly distributed workforce.

- Semi-scheduled Activities - A completely asynchronous course would allow students to set their own pace, but it would also mean that some student might be working on any part of the program of study at any given time. This makes it difficult to support group work. For this reason our courses are not asynchronous across the entire term. Instead, we divide each course into a series of one to two-week activity windows. Activities are scheduled for each period, and students participate at times of their choosing within each activity window.

The courses in the on-line program are entirely on-line. There are no face-to-face meetings of any kind. In addition, all the required activities are asynchronous, within the sort of limitations described above. We have used synchronous on-line chat facilities in some of our courses, but it is not a standard part of the online environment, and use has been optional for the students.

\section{B. Assessing Student Performance}

The assessment approach varies somewhat by course but the common elements include grading for participation in on-line discussions, individual assignments, group projects, and tests and exams. When tests and exams are used, they are treated as "take-home" tests would be in traditional classes. That is, they are designed to be open-book and not timed. 
Group projects are common in both the traditional and on-line classes and are generally unpopular with students in both environments. Given that our student population is primarily part-time, scheduling group work is difficult. This compounds the usual student problems of working with other students with varying abilities and levels of motivation. Overall, the on-line students seem to have no more difficulty with the group work than students in the traditional classes.

\section{Organization and Evolution}

Approaches to course development have varied considerably from course to course. Individual faculty members and others in small teams have converted some courses. For some conversions the primary contributor has been a fulltime faculty member, for others an adjunct person has taken the lead.

The College generally uses a team management approach to curriculum coordination, with a faculty lead for each course. This person typically either has led the development of the on-line version or served as advisor to the effort. Because the goal is to make each on-line course equivalent to the traditional course, formal faculty approval is not an issue in conversion.

Support for course development comes from faculty members who were early adopters, and from the staff supporting the on-line degree. The faculty members serve as mentors, discussing teaching approaches and sharing examples of various approaches. The staff members introduce faculty members to the on-line environment, address procedural issues, create a standard shell version of the course, and perform system administration tasks related to the new course.

Although we have enough courses on-line to offer the degree, we are still converting additional courses for on-line offering in the M.S.I.S. Courses already converted have been offered anywhere from one to eight or more times.

\section{RESULTS}

There are a variety of factors that characterize the importance of the Drexel on-line initiative to the faculty:

- We are offering an entire degree, not individual courses.

- This is an initiative of the College rather than the University.

- On-line courses are taught by regular faculty and most of the people who teach in the traditional M.S.I.S. have already taught in the on-line program.

- About $35 \%$ of the students in the M.S.I.S. are on-line students.

Taken together, these factors mean that the on-line degree program has become a substantial, ongoing part of the work of the College. In recognition of this, we have been working recently to integrate operation of the on-line program with the traditional offerings of the College. During the startup phase of the on-line degree, functions such as marketing and student recruitment, admissions, and student advisement were handled separately in at least some aspects. Over the past year, we have been integrating these tasks with the traditional operation. This effort has been simplified since many of the traditional operations have been moving on-line during the same time.

For faculty members, this integration of workload raises different issues. For most faculty members in the College, teaching on-line has moved from being a voluntary activity to a routine assignment. Most on-line teaching assignments are made by administrative decision as part of the normal instructor scheduling process.

In addition to the existing workload, there have been several discussions within the faculty about expansion of our on-line offerings, including the possibility of certificate programs and additional degrees. These options raise the prospect of involving still more of the faculty in on-line teaching on a regular, ongoing basis. 
In considering this situation, we felt that this was an important juncture in the evolution of the Drexel project, and that it was a key time to check on faculty opinion about the project. To this end we surveyed the faculty about online education and its role in the College.

\section{A. Faculty Survey}

Broadly speaking, the goal of the survey was to solicit faculty input about our ALN project. We wanted to provide an opportunity for faculty to step back from the work and comment on what we had built and offer opinions about how we might proceed from here. We were also particularly interested in how the faculty felt about the notion of online teaching as a regular, permanent part of their workload.

To encourage honest input, especially by non-tenured faculty, the survey responses were anonymous. The survey was designed to be quick to complete in an attempt to achieve a better response rate on key items at the expense of obtaining more detailed data. The survey consisted primarily of a series of statements to which respondents were asked to indicate their agreement or disagreement using a seven-point scale. In addition to the quantitative response, the survey allowed for comments on each statement and included several open-ended questions inviting comment about concerns and potential of ALN.

We received 19 responses out of a possible 26. In the paragraphs that follow we present some of the results.

\section{General Opinion of ALN}

The survey contains two items that address the value of ALN generally. The first addresses learning effectiveness via ALN. Figure 2 shows the survey statement and responses. Sixty-eight percent of the faculty agrees that learning by ALN can be effective. Those disagreeing did not provide explanations. Those agreeing offered caveats that learning outcome would be affected by factors including instructor communication skill, student self-discipline, support, and the type of material being taught. For example:

"In my experience I think the outcomes were as good, but this is a function of the communication skills of the instructor and the motivation of the students. Students in on-line courses have to be highly motivated to be successful. And faculty have to have the skills and support to teach in this environment."

\begin{tabular}{|l|lllllllll|}
\hline $\begin{array}{l}\text { On-line education can produce learning outcomes as good } \\
\text { or better than traditional, face-to-face education. }\end{array}$ \\
\hline $\begin{array}{l}\text { Response } \\
\begin{array}{l}\text { Frequencies } \\
:\end{array}\end{array}$ & 5 & 5 & 2 & 2 & 4 & 0 & 1 & \\
Scale: & Agree & 1 & 2 & 3 & 4 & 5 & 6 & 7 & Disagree \\
\hline
\end{tabular}

Figure 2. Learning Outcome On-line vs. Traditional

In spite of the fairly mild agreement about learning effectiveness, respondents were much more decisive about whether on-line education should be a significant, permanent part of the College, with $95 \%$ agreeing that it should (Figure 3). The comments pointed to a variety of factors including opportunity for market expansion, competition by other providers, and increasing interest among students. For example:

"Our competitors are offering courses this way, so we must do this too. Also, this will allow us to reach a segment of the market that it would not be possible to reach via on-campus courses."

On-line education should be a significant, permanent part of this college. 


\begin{tabular}{llllllllllll|}
$\begin{array}{l}\text { Response } \\
\text { Frequencies: }\end{array}$ & & 12 & 5 & 1 & 0 & 1 & 0 & 0 & \\
& & & & & & & & & & & \\
Scale: & Agree & 1 & 2 & 3 & 4 & 5 & 6 & 7 & Disagree \\
\hline
\end{tabular}

Figure 3. Permanent Role for ALN

\section{Types of ALN Programs}

Another set of items allowed respondents to indicate the types of educational programs that they consider appropriate for delivery via ALN. The first group of items considers whether delivering entire degrees via ALN is appropriate (Figure 4). The responses to these items vary substantially by degree type. There is considerable support for the current ALN degree, the M.S.I.S., and a second professional master's degree oriented toward Library and Information Science, the M.S. Eighty-nine percent of respondents support ALN delivery of these degrees. The picture is reversed however for both the Bachelor of Science in Information Systems (B.S.I.S.) and the Ph.D. For the B.S.I.S. only $12 \%$ agree and for the Ph.D. only $21 \%$ agree that an ALN degree should be offered.

\begin{tabular}{|c|c|c|c|c|c|c|c|c|c|}
\hline \multicolumn{10}{|c|}{$\begin{array}{l}\text { In addition to face-to-face programs, the college should offer the following educatic } \\
\text { on-line: }\end{array}$} \\
\hline \multicolumn{10}{|l|}{ Response } \\
\hline \multirow[t]{4}{*}{ Frequencies: } & & 1 & 0 & 1 & 3 & 4 & 5 & 3 & B.S.I.S. \\
\hline & & 9 & 6 & 2 & 1 & 0 & 0 & 1 & M.S.I.S. \\
\hline & & 9 & 3 & 5 & 0 & 0 & 0 & 2 & M.S. (L.I.S.) \\
\hline & & 2 & 0 & 2 & 1 & 5 & 0 & 9 & Ph.D. \\
\hline Scale: & Agree & 1 & 2 & 3 & 4 & 5 & 6 & 7 & Disagree \\
\hline
\end{tabular}

Figure 4. On-line Delivery of Full Degrees

This variation by degree probably reflects both experience and culture within the College. The B.S.I.S. students are primarily traditional-age undergraduates. While we have not offered the B.S.I.S. via ALN, we have offered quite a few individual courses to these students via ALN. The general consensus among faculty seems to be that these students like ALN less and do less well at it than our part-time graduate students. We have not had time to investigate this issue systematically, but one possibility is that our style of ALN, with heavy dependence on student participation and interaction, works less well with younger, less experienced students.

Respondents did not comment on the doctoral program directly. However, from comments in other discussions faculty seemed to clearly feel that extensive, informal interaction is an essential part of the doctoral experience and that this would not be possible on-line.

The faculty respondents are much more agreeable to offering individual courses and non-degree programs via ALN (Figure 5). This included support for ALN offerings of some upper-level B.S.I.S. courses (100\%), some master's courses $(95 \%)$, some doctoral courses $(84 \%)$, post-baccalaureate certificates $(89 \%)$, and continuing education courses $(95 \%)$.

\begin{tabular}{|c|c|c|c|c|c|c|c|c|}
\hline \multicolumn{9}{|c|}{$\begin{array}{l}\text { In addition to face-to-face programs, the college should offer the } \\
\text { following education on-line: }\end{array}$} \\
\hline \multicolumn{9}{|l|}{ Response } \\
\hline \multirow[t]{3}{*}{ Frequencies: } & 11 & 6 & 2 & 0 & 0 & 0 & 0 & $\begin{array}{l}\text { Upper level B.S.I.S. } \\
\text { Courses }\end{array}$ \\
\hline & 14 & 4 & 0 & 0 & 0 & 0 & 1 & $\begin{array}{l}\text { M.S.I.S. or M.S. (LIS) } \\
\text { Courses }\end{array}$ \\
\hline & 11 & 3 & 2 & 1 & 0 & 0 & 2 & Ph.D. Courses \\
\hline
\end{tabular}




\begin{tabular}{|c|c|c|c|c|c|c|c|c|c|}
\hline & & 14 & 2 & 1 & 1 & 0 & 0 & 1 & $\begin{array}{l}\text { Post-Baccalaureate } \\
\text { Certificate }\end{array}$ \\
\hline Scale: & Agree & 1 & 2 & 3 & 4 & 5 & 6 & 7 & Disagree \\
\hline
\end{tabular}

Figure 5. On-line Delivery of Selected Degree Courses and Other Offerings

Some of the more cautious views can be characterized by the following comment:

"I don't think we should offer any degree programs completely on-line. Students need to have some face-to-face contact with faculty and other students. But I think some courses could be offered on-line for master's degree students, nontraditional undergrads, and continuing ed/certificate programs."

\section{ALN Teaching Load}

A final selection of items provides some insight into faculty reaction to the prospect of ALN as a normal part of teaching load. First are two items that relate to the working environment of an on-line instructor.

Eighty-three percent of respondents indicate that they would be willing to contribute to a shared set of course materials for use within the College for an on-line course. This is not too surprising given that the College has a tradition of team-managed curriculum, and materials are routinely shared for traditional courses too. At the same time, there was a concern for maintaining flexibility and creative contributions as exemplified in this comment:

"Let's not reduce the ability for an instructor to give forth their education and wisdom-let's not turn them into messengers."

Note too that the question explicitly limits the concept of sharing to materials "for use within the College." The intellectual property issues raised by on-line education are still the subjects of ongoing discussion at Drexel, and we wanted to avoid that discussion in this survey. Getting any clear sense of faculty opinion on those issues would require a separate survey.

In considering the issue of personal satisfaction, $78 \%$ of respondents indicate that they consider face-to-face teaching to be a "much more satisfying experience" (Figure 6). Comments here mostly related to the loss of communication bandwidth in ALN education. For example:

"For me, on-line teaching became a form of sensory deprivation. I found it frustrating not being able to see and hear my students and I encountered many more miscommunications and conflicts with students than I did teaching face-to-face."

\begin{tabular}{|c|c|c|c|c|c|c|c|c|c|}
\hline \multicolumn{10}{|c|}{$\begin{array}{l}\text { For me, teaching face-to-face is (or would be) a much more satisfying } \\
\text { experience. }\end{array}$} \\
\hline \multicolumn{10}{|l|}{ Response } \\
\hline Frequencies: & & 7 & 3 & 4 & 1 & 1 & 1 & 1 & \\
\hline Scale: & Agree & 1 & 2 & 3 & 4 & 5 & 6 & 7 & Disagree \\
\hline
\end{tabular}

Figure 6 - Faculty Satisfaction Teaching On-line vs. Traditional Classes

The next two items provide an interesting contrast related to faculty obligation to teach (Figure 7). The respondents are quite ambivalent as to whether faculty should be expected to teach on-line as a normal part of teaching load. Only $39 \%$ agree that this should be expected and an equal percentage disagrees. $22 \%$ chose the neutral answer, more 
than for any other question. Some of the disagreement related to belief that faculty should be assigned according to simple personal preference. Other comments linked choice of assignment with success in teaching, such as:

"For it to be effective, people need to feel comfortable with this mode of teaching."

In contrast with the question of whether faculty should be expected to teach on-line, a separate item asked whether the faculty did in fact feel obliged to teach on-line given the College's commitment to ALN. Here the response was anything but ambivalent, with $95 \%$ agreeing that they did feel obliged.

Taken together, these two items might be seen as an indicator that there is some limit to the level of routine on-line teaching with which the faculty would be comfortable. Two additional items provide some interesting quantification of what level of on-line teaching might be acceptable to the faculty (Figure 8). Respondents were asked what they would consider an acceptable on-line teaching load to be based on the College commitment to ALN and based purely on personal preference.

As might be expected from prior discussion, the personal preference responses are lower, but not that low, and not widely different from the response based on College commitment. On average, faculty say they would be willing to teach $66 \%$ of their classes on-line given the College commitment to ALN. On average they would be willing to teach $50 \%$ of their classes on-line based strictly on personal preference. Either of these levels would be quite adequate to support our on-line program currently and for the near future.

\begin{tabular}{|c|c|c|c|c|c|c|c|c|c|}
\hline \multicolumn{10}{|c|}{$\begin{array}{l}\text { All full-time faculty members should be expected to teach on-line } \\
\text { as needed as part of regular teaching load. } \\
\text { Given the College's commitment to on-line education, I feel obliged to teach on-line. }\end{array}$} \\
\hline \multicolumn{10}{|l|}{ Response } \\
\hline \multirow[t]{2}{*}{ Frequencies: } & & 4 & 2 & 1 & 4 & 1 & 4 & 2 & $\begin{array}{l}\text { Expected to teach } \\
\text { on-line }\end{array}$ \\
\hline & & 11 & 3 & 0 & 2 & 0 & 1 & 1 & $\begin{array}{l}\text { Obliged to teach } \\
\text { on-line }\end{array}$ \\
\hline Scale: & Agree & 1 & 2 & 3 & 4 & 5 & 6 & 7 & Disagree \\
\hline
\end{tabular}

Figure 7. Expectation and Feeling of Obligation to Teach On-line

\begin{tabular}{|c|c|c|c|c|c|c|c|c|c|c|c|}
\hline \multicolumn{12}{|c|}{$\begin{array}{l}\text { Given the College commitment to on-line education, I am agreeable to teaching } \\
\text { Based strictly of my class sections on-line. } \\
\begin{array}{r}\% \text { of my class sections on-line. } \\
\text { on onsiderations, I would choose to teach }\end{array}\end{array}$} \\
\hline \multicolumn{12}{|l|}{ Response } \\
\hline \multirow[t]{2}{*}{ Summary } & 1 & 0 & 2 & 1 & 2 & 1 & 1 & 1 & 0 & 6 & $\begin{array}{l}\text { Given IST } \\
\text { commitmen }\end{array}$ \\
\hline & 3 & 0 & 2 & 3 & 2 & 0 & 0 & 2 & 0 & 4 & $\begin{array}{l}\text { Personal } \\
\text { choice }\end{array}$ \\
\hline $\begin{array}{l}\text { Categories } \\
\text { Upper Bound } \\
(\%)\end{array}$ & 10 & 20 & 30 & 40 & 50 & 60 & 70 & 80 & 90 & 100 & \\
\hline
\end{tabular}

Figure 8. Percent of Teaching Load On-line

Some of the complexity of dealing with faculty issues in on-line education is exemplified by an excerpt provided by Michael Atwood, one of the authors of this paper. Atwood is fairly new to the Drexel ALN program, but has spent his career studying problems of human-computer interaction (HCI). His work has included designing and 
implementing intelligent tutoring systems and a group memory system that supports different-time, different-place communication among hundreds of community college students throughout New York and New England.

In considering the question of faculty satisfaction during the term when he was teaching his first ALN class, Atwood offered the following comments:

When I first read the description of papers in this category, my initial reaction was "Great! Faculty satisfaction is definitely something we should know about." This was soon followed, as initial reactions often are, by a second thought "What, exactly, does faculty satisfaction mean?"

Faculty satisfaction is not a unitary dimension on which we can place ourselves with a single number. Rather, it is a combination of factors; complicated, no doubt, by large individual differences of opinion as to what those factors are. So, if we can't effectively talk about faculty satisfaction across a range of faculty, it's probably best to begin with individuals. So, here's my view on what faculty satisfaction means.

Since the pitfalls (primarily) and benefits (secondarily) will greatly influence my satisfaction with ALN, I'll briefly describe what I see as the four main pitfalls — bandwidth, delays, terseness, and uncertainty.

Face-to-face communication has a lot of bandwidth and we are all well trained in how to use that bandwidth. It is also clear that communication suffers as bandwidth declines. Researchers studying early video conferencing systems, for example, were surprised that people reported significant declines in communication effectiveness. They then deduced that this was due to moving communications practices that were refined in a 3-D world into a 2-D space. Gesture is important in face-to-face communication and much gestural information is lost when communication is limited to two dimensions. Communication suffers even more with ALN. Communication is basically a string of text, slightly better, at best, than a one-dimensional communication. In the classroom, we can tell if a student is inspired, lost, or bored by what we present. With ALN, we can't even tell if the message that is sent is even received. (More on this later.)

Communication delay is a significant variable in face-to-face communication. In a normal conversation, a delay of 15 seconds or so in responding begins to feel uncomfortable and signals that we have lost either the conversational thread or the attention of the other person. When we ask a question in the classroom, we have an expectation about how long a student should take to formulate a response. Further, conversations are grounded in context; we trade information about what we see as the current state of the world. As delays move from seconds to hours, the changing context causes the value of information to decline sharply.

Written communication is terser than spoken communication. Discussions over E-mail are briefer than those over a telephone or those face-to-face. For most, typing takes both more effort and more time than speaking. When the time and effort allocated for communicating are met, communication ends. While a decrease in quantity of communication doesn't necessarily mean a decrease in quality, in my experience this is usually the case.

Asynchronous communication is uncertain. Dropping a letter into a mailbox, sending a note through E-mail, or posting a note to a bulletin board does not guarantee that it will be received. Communication failures do occur but, because it is time-consuming and expensive to continually monitor to guarantee that communication is completed, we rarely do. Because a missed message 
would mean a common context wasn't being maintained, the message that is received may be interpreted much differently than what was intended when it was sent.

So, how does this relate to satisfaction with asynchronous learning? Satisfaction with ALN basically means "can I accomplish what I intend to accomplish with a reasonable amount of time and effort." What is reasonable is based on past experiences and since I have much more experience with classrooms than with ALN, reasonable is based on the amount of time and effort classroom teaching takes. Since this time and effort is increased by the pitfalls outlined above, satisfaction is primarily determined by the time and effort it takes to avoid these pitfalls.

So, the simple answer to "Am I satisfied with ALN as a vehicle for delivering education?" is no. My goal is to give students a chance to acquire and demonstrate competency in defined areas. I can do this in the classroom, but the time and effort required to try to overcome the pitfalls of limited bandwidth, delay, terseness, and communication uncertainty in the ALN is extra work. That is, the energy used to battle these problems detracts from that available to prepare lecture notes, write final exams, grade assignments, and talk one-on-one with students.

My satisfaction with ALN may be affected by the fact that I teach a course in human-computer interaction and focus on the design of interactive systems. Design is a process that involves communication and collaboration among a team of designers and others. Further, design is an illstructured problem in which students must define the artifacts they will reason with and communicate about rather than begin with a predefined set of artifacts. Effective communication is crucial to learning and doing design. So, students work in design teams and they have the same frustrations with bandwidth, delay, terseness, and communication uncertainty in student-to-student communication as I have with instructor-student communication. They also lose time and energy battling these pitfalls and this reduces the energy available to concentrate on learning.

While it is possible that asynchronous learning can be as effective as classroom learning, parity in effectiveness may come at the cost of greater effort. Students who see clear benefit to asynchronous education must be willing to balance this benefit against this cost. For educators and educational institutions, the cost of greater effort must be balanced against the benefit of educational outreach.

ALN brings education to some students who otherwise would not have the educational opportunity. Providing more education to more people seems like a good thing. Universities should have an obligation to reach out to communities who would otherwise be denied educational opportunity. On-line education, and other outreach programs, should be a significant part of university programs and we should learn to do them better.

A second opportunity is research. In design, research and teaching are highly interrelated. I admit a bias here, which comes from working in the field of human computer interaction [HCI]. $\mathrm{HCI}$ is a balance between application and research. While there is basic research that is relevant to HCI, there is no basic research of HCI. HCI is an applied science and we can only study it and observe it in the context of its application. HCI is an artificial science; the focus is on artifacts, not natural phenomena. We can only advance the field by building and studying artifacts. ALN provides such an artifact. One of the hardest problems in HCI is how to facilitate the communication among people involved in designing and using systems. From this perspective, doing research on communication among designers while simultaneously designing mechanisms through which students learning about design can communicate are highly complementary activities. 
Do the costs of using the ALN outweigh the benefits? If the ALN were a well-designed, skillfully implemented, totally unchangeable entity, low satisfaction would be fatal for continued use. But if we view the ALN as the current state of an iterative design process, low satisfaction is a very good thing! I believe Christopher Alexander's claim that design is "a negative process of neutralizing the incongruities, or irritants, of forces which cause misfit." The ALN does not work well as it might, but we know where some of the irritants are and we can direct our efforts at alleviating them. The benefit of educational outreach significantly outweighs the cost associated with using and improving the ALN.

In summary, my satisfaction with the current ALN as an educational delivery system is pretty low, but I will continue to use it. The benefit of educational outreach is significant. And for me, the integration of research and teaching is a significant benefit. The primary "extra cost" of using the ALN is in overcoming inefficiency in communication, and understanding how to make communication more effective and efficient is key to studying interactive-systems design.

I started by saying that satisfaction involves many factors and even means different things to different people. This makes it hard to quantify. But, I expect there are a few things most of us would agree on-ALN is not as good as it might be, but it is worth doing and we all have the opportunity to make it better.

\section{B. Conclusions}

Overall the survey seems to show broad support for on-line education among the faculty, tempered by some sources of concern. There is strong agreement that the College should continue work in this area, although there are clearly differences in the types of degrees the faculty feel are most appropriate for on-line delivery. There is some concern about the effectiveness of on-line education compared to traditional education. There is also some personal preference for teaching face-to-face. However, many of the faculty are willing to have a substantial portion of their teaching assignment be on-line.

\section{REFERENCES}

1. Andriole, Stephen J., Lytle, Richard H., and Monsanto, Charlton A. Asynchronous learning networks: Drexel's experience. T.H.E. Journal, Vol. 23, No. 3, pp. 97-101, October, 1995.

2. Hislop, Gregory W. Working professionals as part-time on-line learners. To be printed in an upcoming volume of the Journal of Asynchronous Learning Networks, 2000.

3. Hiltz, Starr Roxanne. The Virtual Classroom, Norwood, NJ: Ablex Publishing Co., 1994.

\section{ABOUT THE AUTHORS}

Gregory W. Hislop is a faculty member and former Associate Dean in the College of Information Science and Technology at Drexel University. Dr. Hislop leads the curriculum management team for the software and information systems degrees and directs evaluation of the College's on-line degree program. Prior to coming to Drexel, Dr. Hislop spent about twenty years working in government and industry as a staff member, manager, and consultant. Dr. Hislop holds degrees in economics, computing science, and information studies.

Contact: College of Information Science and Technology, Drexel University, 3141 Chestnut Street Philadelphia, Pennsylvania 19104-2875; Telephone: 215-895-2179; Fax: 215-895-2494; E-mail: hislop@drexel.edu.

Michael E. Atwood is a faculty member in the College of Information Science and Technology at Drexel University. His teaching and research interests include human-computer interaction, computer-supported cooperative work, and artificial intelligence. Prior to joining the Drexel faculty in 1998, Dr. Atwood spent over twenty years managing research and development in industry. 
Contact: College of Information Science and Technology, Drexel University, 3141 Chestnut Street, Philadelphia, Pennsylvania 19104; Telephone: 215-895-6273; $\quad$ Fax: 215-895-2494;

E-mail: michael.atwood@cis.drexel.edu. 



\title{
ALN Teaching as Part of Routine Faculty Workload
}

\author{
Greg Hislop, Michael Atwood
}

\section{Discussant: Scott Johnson, University of Illinois at Urbana-Champaign}

While the Hislop and Atwood paper addresses a variety of issues related to on-line instruction, this response will focus on the issue of on-line teaching becoming a part of routine faculty workload. Faculty in the Department of Human Resource Education (HRE) at the University of Illinois view on-line teaching as a part of their everyday responsibilities and they make no distinction between teaching on-line and teaching on-campus. We have explicitly tried to eliminate any possible distinction between on-line and on-campus teaching. We have adopted the perspective that our job as faculty is to teach and it does not matter if that involves teaching off-campus, face-toface, or on-line. This means we may be asked to teach small seminars, large classes, weekend courses, and evening courses off campus. For each of these assignments we may teach in a face-to-face format or on-line; it does not matter. This approach is not true for all programs. Many programs are trying to maintain two sets of faculty, an online faculty and a face-to-face faculty. Other programs are viewing on-line teaching as an extra responsibility, which leads to the problem of how to compensate faculty for overload assignments. Sustainability is a difficult goal to reach when we try to support dual programs or compensate faculty for every new activity.

Instead of asking the question "Should on-line teaching be part of routine faculty workload?" we should be asking the question "How can we make on-line teaching a part of routine faculty workload?" The answer to this question seems to lie in the match between the faculty's on-line activities and responsibilities and the existing department culture. Both the Drexel program and the HRE program have addressed the faculty workload problem by incorporating on-line activities into the everyday culture of faculty roles and responsibilities.

To integrate on-line faculty workload into the routine activities of faculty one must first examine the existing departmental culture. This involves responding to four key questions:

\section{- How do we currently assign teaching assignments?}

This decision is typically based on several factors. Is the individual faculty member well prepared to teach the course? Does the faculty have the experience and professional preparation to teach the course? Does the faculty have a personal interest in teaching the course? Is there a historical ownership for teaching the course? In many cases, once a faculty member develops and teaches a course, it is his/her course to teach in the future until a decision is made to pass it on to someone else. If these are the questions we ask when assigning teaching assignments for our campus courses, then the same concerns must be addressed when assigning on-line teaching responsibilities.

\section{- Do we treat all faculty the same?}

Routine faculty workload does not refer to a standard that fits all faculty equally well. While each department has an expected teaching load for its faculty, the typical load is rarely an indication of actual teaching loads during a semester. Routine faculty workload is anything but routine. Especially when comparing teaching loads of faculty who are at different stages of their careers. Junior faculty are often assigned the large introductory courses that many senior faculty do not want to teach. New faculty must spend a great deal of time writing research proposals for funding. The pressure to obtain funding to support their research often conflicts with their interest in teaching. This creates a stressful situation for junior faculty who must find time to establish their program of research and yet meet the expectations of developing and conducting quality instruction. Without funds to support their research, junior faculty are not able to reduce their teaching loads through course buyout arrangements. 


\section{FACULTY WORKLOAD}

In contrast, senior faculty are often assigned to teach smaller more specialized courses and graduate seminars. These senior faculty also have established research programs, which often results in reduced teaching loads. The point of this discussion is to highlight the differences in teaching assignments that exist for higher education faculty. If we currently base teaching assignments and loads on individual situations and capabilities, this should be true for both on-campus and on-line courses.

\section{- What is the faculty member good at?}

Another issue to look at is the areas in which individual faculty excel. Faculty strengths need to be matched to the delivery method. Just as students have preferred methods of learning, faculty have preferred methods of teaching. The critical questions to be answered include "Will our best face-to-face instructors be the best on-line instructors?" and "Can our worst face-to-face instructors become good on-line instructors?" Some faculty thrive on their role as presenters of information and being perceived as knowledgeable authorities on the subject matter. Other faculty shy away from the role as performer and prefer to assist students as a coach and mentor. Matching faculty strengths to the delivery method seems to be the ideal method of enhancing instructional programs.

\section{- What motivates individual faculty?}

Should on-line faculty be compensated differently than regular faculty? Since many on-line programs originate with funds to support the development of courses, but not the ongoing offering of the courses, it is important that the compensation issue be viewed long term, assessing whether short-term policies on compensation are affordable after the development funds are exhausted. Many programs offer faculty incentive packages worth several thousand dollars to teach an on-line course. What happens when the money is no longer available to support these special arrangements? How will faculty respond when they are accustomed to receiving special allocations for teaching on-line and are then told that there is no longer any money available? Rather than creating a special compensation package to entice faculty to enter online, department leaders should use the same strategies that are used for on-campus compensation. This may involve considering what motivates each individual faculty member, rather than establishing the flat fee arrangement that many programs are using. Some faculty may be motivated by release time during the semester of course development, others are interested in summer support or new computers, while others are interested in recognition, personal interest in innovation or research opportunities. The bottom line is that compensation packages should be sustainable in the long term and they must match the current practices that are used for the on-campus program.

We need to plan carefully as we expand our efforts in on-line teaching. One approach is to create two separate administrative systems for managing on-line and campus-based instruction, each relying on different forms of faculty rewards and incentives to encourage involvement. The preferred option, as described in the article by Hislop and Atwood, is to integrate the development, delivery, and administration of on-line teaching into the existing workload of faculty. To be successful with this approach we must view on-line teaching as just one of many ways to engage in teaching instead of treating it as an extra responsibility for faculty.

\section{ABOUT THE DISCUSSANT}

Scott Johnson is an Associate Professor in the College of Education at the University of Illinois. He has been involved in technical education and human resource development for over 20 years as a public school teacher, an instructional designer in industry, and as a teacher educator at the university level. Dr. Johnson specializes in instructional design, instructional methods, and instructional technologies. He is currently the director of HRE Online, an on-line program leading to a master's degree in Human Resource Development.

Contact: Department of Human Resource Education, University of Illinois at Urbana-Champaign, 350 Education Building, 1310 South Sixth Street, Champaign, Illinois 61820; Telephone (Voice): 217-333-0807; Fax: 217-2445632; E-mail: sjohnson@uiuc.edu. 